\title{
Does the Fonetik Spelling System improve Standard Spelling Scores?
}

\author{
lan Johnson
}

RTLB, Westland Cluster

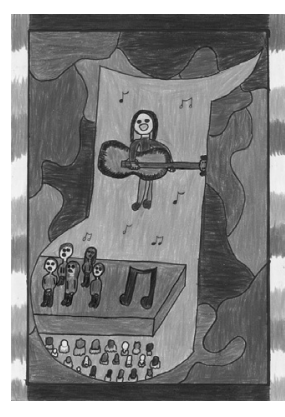

\section{ABSTRACT}

This seven month trial was undertaken to determine if the Fonetik spelling system (Jackson, 1994) enabled students with and without spelling difficulties to enhance their regular spelling scores. A sample of 270 students aged between 8 and 13 years were involved. The students were based in 8 schools within an RTLB cluster. The Fonetik system was introduced to all the students within their regular classroom settings. The results indicate that Fonetik was successful in increasing regular spelling scores for students with spelling difficulties and that it can be successfully implemented in schools with guidance from RTLB. This matched the conclusions of the first trial conducted by Croft and Boyd with the support of NZCER (1993).

\section{RESEARCH}

\section{Practice Paper}

Keywords: Dyslexia, electronic spellchecker, phonetic, special needs, spelling.

\section{INTRODUCTION}

This school-based implementation trial aimed to identify if Fonetik could improve regular spelling scores for students who were struggling with spelling. The aims of the trial were to:

1. Improve regular spelling scores for all students

2. Identify if the students with low initial spelling scores targeted by Fonetik increased their scores in comparison to their more-able peers.

3. Clarify if one particular year group benefited more than other year groups.

4. Assess the effectiveness of Electronic Phonetic Spellcheckers (EPS) to support the Fonetik system.

5. Gather teacher feedback upon the effectiveness of the Fonetik system.

The purpose of the trial was to identify if Fonetik was an appropriate intervention to assist students with spelling difficulties.

\section{BACKGROUND TO THE TRIAL}

Fonetik is fundamentally different from other spelling programmes because it teaches struggling spellers how to spell a word phonetically if the standard spelling cannot be recalled. It targets students who find they struggle not only with spelling but with their written language output.

Moseley (1993) concluded that poor spellers do not have poor oral language vocabulary. He found that poor spellers commonly pick easy to spell and short words. They also repeat words they know in their writing rather than risk using ones they do not. This means that there is a lack of risk-taking with spelling which reduces their ability to put ideas on paper. Kervin and McKenzie (2005) found that pressure put on students to use correct spelling is one of the biggest barriers to writing.

The outcome of such pressure is noted by the Ministry of Education (MOE) (2008) who recognise the effect of poor spelling on students' self-esteem and note that '...there are undoubtedly emotional and social consequences' (p.44). There is little doubt that students with limited spelling skills will write less to avoid making mistakes. The MOE has stated that expertise in spelling is essential to writing (Jackson, 2008a). This abandons the MOEs whole language process writing policy which maintained that spelling skills were acquired by incidental learning.

Gentry (2001) adds that 'all children can become expert spellers..... the ones who do not are probably lazy' ( $p .1)$ and identifies this as a false assumption of teachers along with 'expert spelling is caught from reading and writing' ( $p .1)$. These sentiments may be true for some students but for others it may be that the strategies taught to them for spelling have not been assimilated or that they have a barrier to their learning such as dyslexia. In this case we owe it to our students to continue looking for effective remedial spelling programmes which incorporate the use of electronic aides like word processors, EPS or predictive text for instance.

Fonetik meets a number of criteria identified in several publications (MOE, 2006, 2008) which identify the need to equip students with the skills needed to make themselves understood via written communication. They indicate that effective spellers should write words and say them aloud to help them learn spellings and may even exaggerate pronunciation using syllabification (as in Fonetik). MOE add that in any class a proportion of the students will write words "as they sound" (phonetically) For example "caught" may be written as "cort" or "kort". MOE writes that dictionaries are not always helpful for such students 
as they may not be able to identify the correct initial word for example "uround" for "around". The use of Fonetik and EPS may circumvent this issue because the EPS would provide the correct spelling from the phonetic attempt.

MOE (2006) indicate that 'a phonetic spellchecker is useful for poor spellers because it is organised by sounds rather than letters' (p.162). EPS are used in the UK (British Dyslexia Association, 2009) and are recognised to provide correct spellings from "even quite strange" spelling attempts. These ideas are incorporated in the Fonetik system and following Michael and Jackson's (2003) seventh succesful field trial of Fonetik in Western Australia, the system was implemented at a school-wide level.

Kervin and McKenzie (2005) identify that good spelling involves flexible and strategic problem-solving and highlights the importance of students being aware of a variety of strategies to help them spell words. Surely then it is important to expose students to new systems (MOE, 2008a) to assist them engage with spelling and thus enhance their writing.

Jackson (1994) states that students require only two skills to produce a decipherable phonetically regular spelling - knowledge of the five short vowel sounds and the ability to break words into syllables. Fonetik thus unlocks the complexities of written English language by reducing the complex rules and irregularities to only two simple teaching steps. Phonetic spelling patterns are readily recognised and decoded i.e. "stoodents" instead of "students". Phonetically regular spelling attempts are marked with one tick and standard correct spellings are marked with two ticks. Students can then correct phonetic spellings to standard spellings by utilising an EPS. Alternatively the same outcome can be achieved by cooperative proof reading.

With the recognition of spelling attempts in the manner described above students' self-esteem can be raised. Lutz (1986) and Zutell (2009) support this notion by identifying that if schools wish to make use of recent insights into language development then changes in teachers and public attitudes about the need to spell every word correctly are required. This change was achieved in Western Australia following Michael and Jackson's (2003) intervention when existing marking conventions within the test school were altered to recognise phonetic spellings. Rankin's (1994) trial on Fonetik showed that the system improved spelling skills for failing students, so the idea of using phonetic spellings is not new - perhaps just unrecognised.

Croft (2004) indicates that the purpose of writing is to convey information and whilst spelling contributes to the understanding of the message, correct spellings are not always required communicating the meaning within the text. He maintains that students should be encouraged to write using variant spelling codes on first rough drafts.

Jackson (2007) reports that the majority of students with spelling difficulties are boys and that up to twenty percent will be still spelling at the level of the average seven to nine year old by the time they reach secondary school. He adds that whilst secondary schools do offer remediation systems these mostly focus upon reading. This is a problem because reading does not always improve spelling but there is evidence to suggest that improving spelling does improve reading ability. Evidence of Fonetik's success is presented by Jackson (2002) and shows that students made a 39\% gain in correct attempts at spelling and concluded that students who made more gains in phonetic spellings made more gains in regular spellings.

\section{METHODOLOGY}

\section{Description of the Fonetik System}

Jackson (1994) developed the Fonetik system to assist students struggling with regular spelling. Fonetik aims to teach students how to spell in a phonetically regular way, for example "enough" could be spelt "enuf" using a phonetic approach. Fonetik involves teachers recognising phonetically regular spellings as well as standard spellings and seeing them both as recognisable spellings. EPS are used to convert phonetic spellings into regular spellings.

The target student group are those of late primary, intermediate or secondary age level. The students should know letter-sound correspondences and have reading and oral language ability which exceeds their spelling and writing skills.

\section{Description of the electronic spellcheckers}

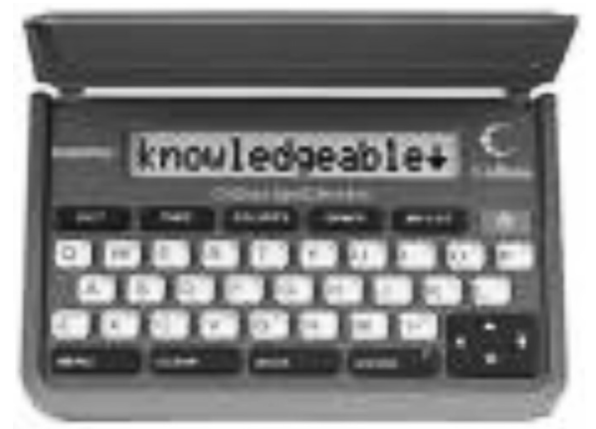

Example of a Franklin electronic spellchecker used during this trial

The Franklin EPS was utilised during this trial. This model is easy to use and proved popular with both teachers and students. Once the student has worked out the Fonetik spelling they type it into the spellchecker and press enter. The regular spelling which most closely matches 
the phonetic attempt is displayed. They retail for $\$ 49.95$ via BDL ( HYPERLINK "http://www.bdlfranklin.co.nz" www.bdlfranklin.co.nz) or Dick Smith electronics. Forty spellcheckers were purchased with the support of the Learning Support Fund and a grant from the Dyslexia Foundation.

\section{Why was Fonetik selected to assist students with spelling?}

A large number of referrals received within the writer's RTLB cluster are for students who are struggling with literacy. A large percentage of those referrals are for students struggling with spelling and written expression with spelling ages often three to four years below their chronological age.

Upon reading the Fonetik guide book (Jackson, 1994) the writer felt that Fonetik would be an appropriate clusterwide intervention The system seemed simple and cheap to implement with the bonus that it could be delivered to whole classes of students no matter what their spelling ability. The system enhances inclusion because it enables students with spelling difficulties to participate alongside their more able peers more easily and is therefore an appropriate intervention for RTLB (MOE, 2007a).

\section{Selection of schools and students}

Eight schools and 16 classes including a total of 270 students were selected for participation. The students were aged from Year 5 (chronological age 9) up to Year 8 (chronological age 13). All of the students within each class were tested. Those absent from pre- or post-testing were not included in the final results.

All members of each class were trained to use Fonetik and had access to the EPS. The trial was designed to enable equal opportunity for all students to make use of the system when they needed help with spelling. By this approach the more-able students would not need to use their "Fonetik" skills as often because they had greater spelling knowledge. Whilst the omission of a control group is not ideal, the analysis of results was able to identify the pre- and post-intervention score changes for students within each of the scoring ranges and identify the success or failure of Fonetik to assist each group.

\section{DATA COLLECTION}

\section{Pre-testing}

Initial testing was conducted in February, 2009 using the South Australian Spelling Test (SAST) Test 'A' (Westwood, 2005). Each class took between 20 and 30 minutes to complete the test. The SAST consists of 70 graded words which are read out and then re read in a sentence to clarify meaning. Students were instructed to attempt all 70 words.
All tests were marked and scored in accordance with Westwood's (2005) instructions. The SAST was selected for the test as it had been normed upon a large representative sample in South Australia in 1993 and 2004. The normative age related bands were:

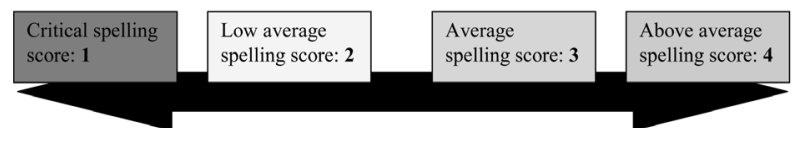

The bold numbers within the boxes 1-4 enabled the students who were most likely to be assisted by Fonetik to be identified from each class groups (those with Band 1 or 2 scores). The remainder of the student sample results in the average (3) and above average (4) attainment bands were also recorded.

\section{Post-testing}

The SAST was re-administered in September, 2009.

All teachers were given a 14 question evaluation of Fonetik following the post test to gain their comments and interpretation of how effective the system had been.

\section{Treatment of results}

The pre- and post-test results were compared and average regular and phonetic spelling scores were obtained. The results were then combined by year groups from all 8 schools enabling an analysis of which year group benefited most from the intervention. By using the SAST normed scale results for standard spellings from pre- and post-tests, students' movement between the four segments were tracked, enabling those who started within the critical and low average ranges in particular to have their progress objectively measured from "hard" empirically-based data. Each student was assigned a score of 1 - 4 from the result of their spelling tests from the normed tables enabling correct standard spelling bands to be ascertained.

\section{Fonetik training outline}

Students and teachers were trained in the Fonetik system following the teaching steps in Jackson's (1994) manual. The main points covered involved letter/sound correspondence, syllabification and encouraging the students to 'spell the word as it sounds' if they did not know the correct spelling.

Students were instructed in their class groups. Initially the students from each class identified as being within the critical and low average spelling ranges were given a 30 minute training session. They were the students who would normally be targeted individually or in small groups and by giving them an extra session their familiarity with Fonetik skills was enhanced. Following this tuition they, along with their remaining classmates and teachers were given two more 30 minute training sessions as a class group. The final session incorporated instruction on how 
to use the EPS. EPS were given to each class dependent upon the number of students within the class. The larger classes had four EPS each with other smaller classes having between one and three.

During the intervention three mentoring sessions within each class and each school were completed. This involved the writer visiting each class revising the Fonetik system with the teachers and students. During the trial period students were prompted and assisted in their regular classes by their teachers to utilise the Fonetik system and the EPS. Teachers encouraged their students to use Fonetik spellings in their draft work when they were unsure of the regular spelling. Following teacher advice on their Fonetik attempts students accessed the EPS. This enabled teachers to reinforce the Fonetik system's steps.

\section{RESULTS}

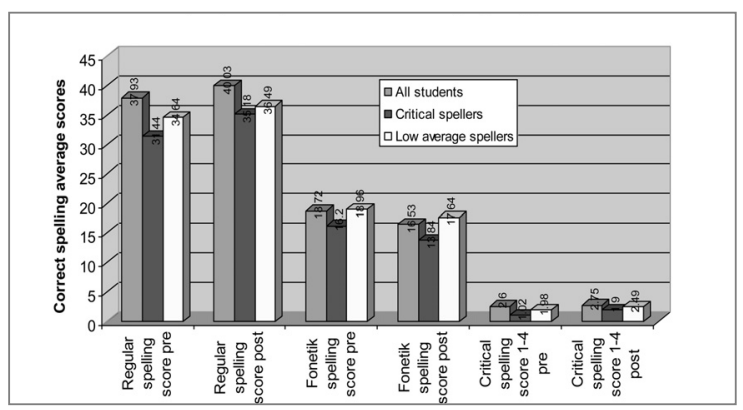

Figure 1: Summary of pre- and post-intervention average spelling scores.

Figure 1 shows:

Students classed as critically-low spellers pre-test had lower phonetic spelling scores than the other two groups. Post-test, the whole samples regular spelling score had increased by an average of 3 spellings. Those classed as low-average spellers improved by 2 spellings whilst the students classed as critical spellers increased by 4 spellings. This indicates that the students whose spelling improved the most were those classed as having the lowest spelling scores initially, Post-intervention, all three groups averages for phonetic spellings reduced, indicating their regular spelling had improved.

The average rating scale score for the whole group rose to 2.75 from 2.60 indicating that the sample as a whole had improved their standard spellings.

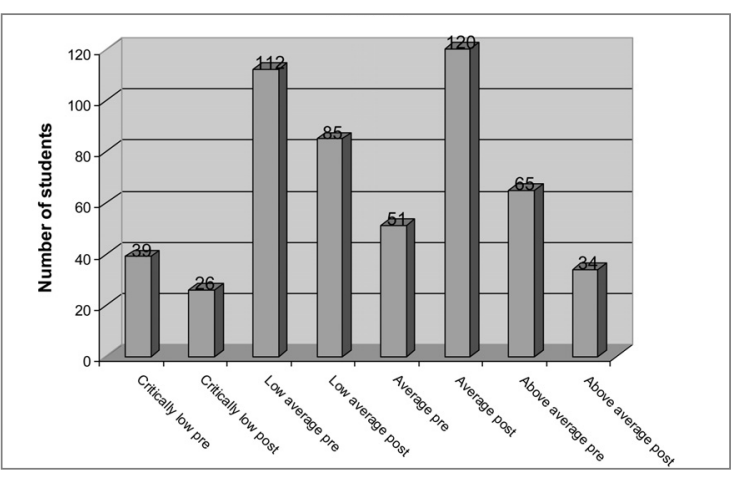

Figure 2: Student numbers within each of the four spelling ranges pre- and post-intervention.

Figure 2 indicates that:

- There was a reduction (13 students) in the number of students within the critically-low spelling band, indicating that they had moved into a higher band.

- The students within the low-average area of the scale reduced by 27 students signifying that they in turn, had moved up the scale.

- The students scoring within the average scale increased from 51 pre test to 120 post-test. This means that of the 69 new students who moved into the average band, 38 students had increased their spelling scores to lift their attainment into the average band.

In summary, the students Fonetik targets from the critical and low-average ranges pre-test had progressed into either the low-average range or average-range following the intervention. A number of the above-average students who Fonetik does not target had regressed into the average range.

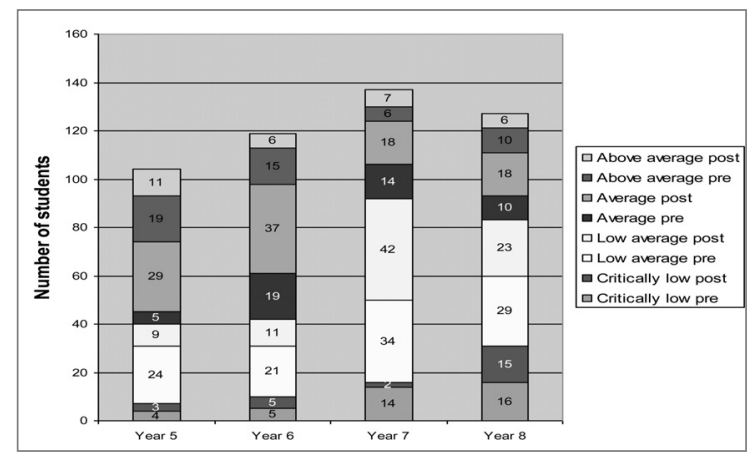

Figure 3: Comparison of the number of students within each spelling score range by year group pre- and post-intervention.

Figure 3 indicates that following the Fonetik intervention:

- Year 5: The average range scores increased by 24 students. The low-average and critical reduced by 16 . This shows that 16 students increased the standard spelling scores and moved into the average band.

- Year 6: No change in the number of critical-range 
students was noted. Students within the low-average range reduced by 10 . Students in the above-average range reduced by 9 . Students in the average range increased from 19 to 37 , indicating that 10 students had moved from the lower ranges into the average range, indicating a trend of improved regular spelling scores.

- Year 7: Students within the critical-range reduced by 12. The low-average range increased by 8 , average range increased by 4 students. The students in the above-average group increased by one. This was the only year group to show an increase in the aboveaverage range, indicating a trend of improved regular spelling scores.

- Year 8: Students in the critical-range reduced by 1.

Students in the low-average range reduced by 6 . Students in the average range increased by 8 . Aboveaverage students decreased by 4 . This indicates that the overall trend for this group was increased regular spelling scores.

\section{Further analysis of results}

- Years 5, 6, 7 and 8 all showed general improvements with students moving up the spelling ranges.

- Year 7 was the only group to improve regular spelling scores in all ranges.

- Years 5, 6, and 8 did not show improved scores for students within the above-average range supporting the idea that Fonetik best supports students with lowaverage and critical spelling scores.

- Six Year 7 students and five Year 8 students jumped two levels across the scoring range from either critical- or low-average range, to the average or above-average ranges respectively.

\section{Teacher feedback following the intervention}

All teachers participating in the Fonetik field trial were given a fourteen question evaluation sheet to assess their views on Fonetik. Twelve evaluations were completed and a summary of comments is outlined under the headings below:

\section{Teachers regular spelling programmes which ran in tandem with Fonetik}

- Essential spelling lists

- Frustrated speller

- Quota spelling

- Smartwords

- Switched on to Spelling

- You can spell (x2)

- Spellodrome

- SpellWrite

\section{On Fonetik}

The 12 respondents identified the system as being easy to implement and that the training and mentoring provided by the RTLB was sufficient. They also agreed Fonetik had a place within the classroom and that they would continue to use it. Teachers unanimously identified the low average spelling students as the group who gained the most from the system followed by the critical speller's.

\section{Electronic Phonetic Spellcheckers (EPS)}

Respondents indicated that the spellcheckers were easy to use and effective. The majority of teachers felt that they were essential to the effectiveness of the system.

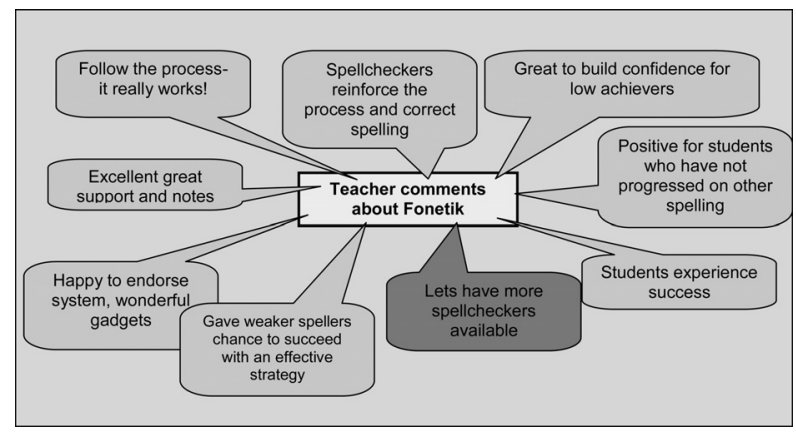

Figure 4: Teacher comments about Fonetik:

\section{DISCUSSION}

The results provide good empirical support for the Fonetik remedial spelling system being more widely used within New Zealand schools. The majority of students improved their regular spelling scores (Figure 1). The students with low or critical spelling scores were able increase their scores in general. Their scores lifted more than students initially in the other ranges (Figure 2). Each year group showed similar positive increases between the ranges, especially between low average and average ranges which Fonetik targets. The EPS were seen as an effective and integral part of the system. Teacher feedback towards the system was extremely favourable indicating it was easy to implement, gave effective results and could run across the curriculum and alongside other spelling programmes.

Teachers should be mindful that Fonetik targets struggling spellers and such students are the ones who will benefit most. Figure 2 shows clear evidence that Fonetik works for the students it was designed for: competent spellers do not benefit from using Fonetik.

Fonetik ran alongside a variety of other spelling programmes and showed that it could be run whilst other spelling programmmes were being utilised. Whilst it was beyond the scope of this trial, future research could be completed to test Fonetiks' effectiveness when used on its own. The results gained by this trial are positive 
in that they demonstrate Fonetik can be implemented within regular cross-curricular classes to assist struggling spellers without compromising the class programme or any existing spelling programme.

The Resource Teacher: Learning and Behaviour (RTLB) team within the eight schools noted significant changes for students whom she had been monitoring for a number of years. She indicated that the Years 7 and 8 students had shown huge improvements on her testing which was also completed in February and September 2009. She informed the writer that the only new programme had been the use of the Fonetik system. This supports the findings of this trial.

A further reason for selecting Fonetik as the remedial spelling system of choice was because it utilises assistive technology in the form of EPS. Even though the EPS are widely available and in use in a number of other countries, many teachers within the writer's cluster were unaware of them. The Information and Communications Technology (ICT) policy identifies the importance of using assistive technology to improve learning outcomes and enable students to participate fully within society (MOE, 2003). Due to the recognition of dyslexia within New Zealand (MOE, 2007) and the government's pledge to assist students diagnosed with dyslexia, the use of electronic spellcheckers should become more common within schools.

\section{CONCLUSION}

This trial has shown clear evidence indicating the effectiveness of the Fonetik spelling system for the students it targets. The teacher feedback was extremely positive and shows that Fonetik can run in association with other spelling systems (which are not supported by empirical data with regard to their efficacy) and be utilised across the curriculum.

The results of the trial show that RTLB can implement the system across their clusters easily and efficiently with motivated class teachers. RTLB can also demonstrate the systems efficacy by utilising the pre- and postintervention assessments and presenting them to their management committees. This trial has also shown that Fonetik can be run as a successful whole-class intervention but indicates that highly competent spellers may not benefit from participation.

The trial was limited as no control group was incorporated into the design. There is scope for further studies to address this deficiency along with assessing the effect of training students within the target groups individually or in small groups away from their class. The trial did not identify if Fonetik influenced written output. It seems plausible however, to suggest that if phonetic spellings are accepted in all class work except for publication copies that written output could be expected to increase.
With a change of heart within our schools and the recognition that pressure for correct spelling reduces written output for our low-ability spellers there is hope that many more of the thoughts and ideas of our students can be captured on paper. By recognising phonetic spellings as an educational achievement in draft work, written output will increase and the confidence of our struggling spellers should lift. They could, in the words of the Literacy Task Force (MOE, 1999), be able to finally write as well as they can speak.

\section{REFERENCES}

British Dyslexia Association. (2009). Small and portable devices. Retrieved October 29, 2009 from: HYPERLINK "http:// www.bdadyslexia.org.uk/about-dyslexia/it-information/smalland-portable-devices.html" http://www.bdadyslexia.org.uk/ about-dyslexia/it-information/small-and-portable-devices. $\mathrm{html}$

Croft, C., \& Boyd, S. (1993). Evaluation of a remedial spelling system for the failing standard four speller. Wellington: New Zealand Council for Educational Research.

Croft, C. (2004). Splrs at wrk: Monitoring progress in spelling using developmental information.Wellington: NZCER.

Gentry, R. (2001). Ten false assumptions about teaching spelling. Australian Council for Education Research. Retrieved October 29, 2009 from: HYPERLINK "http:// www.acer.edu.au/need2know/index.html" http://www.acer. edu.au/need2know/index.html

Jackson, C. (1994). Fonetik: Making sense of spelling. Wellington: Special Education Service.

Jackson, C. (2002). Spelling beyond the dark ages. New Zealand Education Review, 13 (26), 6.

Jackson, C. (2007). Spelling struggles to be heard. The Dominion Post. Saturday, December 1, 2007, (A3).

Jackson, C. (2008). Proven remedial systems needed. New Zealand Education Review, 13 (26), 6.

Jackson, C. (2008a). Letter "The statement on page 5" . New Zealand Education Review, 13 (17).

Kervin, L. \& McKenzie, K. (2005). Keeping the conversation going: Creating a whole school approach to spelling. Conference proceedings: Pleasure, passion, provocation. AATE/ALEA National Conference, 1-4 July 2005: Broadbeach, Qld. Retrieved October 29, 2009 from: HYPERLINK "http://alea.edu.au/site-content/Kervin McKenzie.pdf' http://alea.edu.au/site-content/Kervin McKenzie.pdf

Lutz, E. (1986). Invented spelling and spelling development. ERIC Digest. ERIC Clearinghouse on Reading and Communication Skills. Retrieved October 29, 2009 from: HYPERLINK "http://www.readingrockets.org/article/267" http://www.readingrockets.org/article/267

Michael, J., \& Jackson, C. (2003, April). Introducing the Fonetik spelling system into Lynwood Senior High School, Perth, Western Australia. Report of a controlled field trial. Unpublished manuscript. 
Ministry of Education. (1999). Report of the Literacy Task Force. Ministry of Education, New Zealand. Retrieved November 18, 2009, from: HYPERLINK "http://www.minedu.govt.nz/ / media/MinEdu/Files/EducationSectors/PrimarySecondary/ ResearchAndStatistics/ReportofthLiteracyTaskforce. pdf" http://www.minedu.govt.nz/ /media/MinEdu/ Files/EducationSectors/PrimarySecondary/ ResearchAndStatistics/ReportofthLiteracyTaskforce.pdf

Ministry of Education. (2003). Digital horizons. Learning through ICT. Wellington, New Zealand: Ministry of Education.

Ministry of Education. (2006). Effective literacy practice in Years 5 to 8 . Wellington, learning Media.

Ministry of Education. (2007). Ministry improves understanding of dyslexia. Ministry of Education, New Zealand. Retrieved 18 November, 2009, from: HYPERLINK "http://www. minedu.govt.nz/theMinistry/AboutUs/mediaCentreLanding/ mediaReleaselndex2007/MR007Apr1907.aspx" http://www. minedu.govt.nz/theMinistry/AboutUs/mediaCentreLanding/ mediaReleaselndex2007/MR007Apr1907.aspx

Ministry of Education . (2007a). Resource Teacher: Learning and Behaviour (RTLB): Policy and Toolkit. Wellington: Ministry of Education.

Ministry of Education. (2008). The English Language Learning Progressions, Introductions. Wellington: Learning Media Limited.

Ministry of Education. (2008a). Boys success targeted in new report. Ministry of Education, New Zealand. Retrieved October, 30, 2009, from: HYPERLINK "http://www. minedu.govt.nz/theMinistry/AboutUs/mediaCentreLanding/ mediaReleaselndex2008/MR005May30a.aspx" http://www. minedu.govt.nz/theMinistry/AboutUs/mediaCentreLanding/ mediaReleaselndex2008/MR005May30a.aspx

Moseley, D. (1993). How lack of confidence in spelling affects children's written expression. Set: research information for teachers. 2 (9), 1-4.

Rankin, W.R. (1995). Implementing the fonetic spelling programme. A dissertation in partial fulfilment of the Diploma in the Education of Students with Special Teaching Needs. Wellington College of Education, Wellington, New Zealand.
Westwood, P. (2005). Spelling: Approaches to teaching and assessment. Victoria: ACER Press.

Westwood, P. (2008). What teachers need to know about spelling. Victoria: ACER Press.

Zutell, J. (2009). A student-active learning approach to spelling instruction. Spelling Connections, Zaner Bloser, Columbus, Ohio, USA. Retrieved October, 29, 2009, from: HYPERLINK "http://www.zaner-bloser.com/educator/ products/spelling/index.aspx?id=4820\&view=article" http:// www.zaner-bloser.com/educator/products/spelling/index. aspx?id=4820\&view=article

\section{AUTHOR PROFILE}

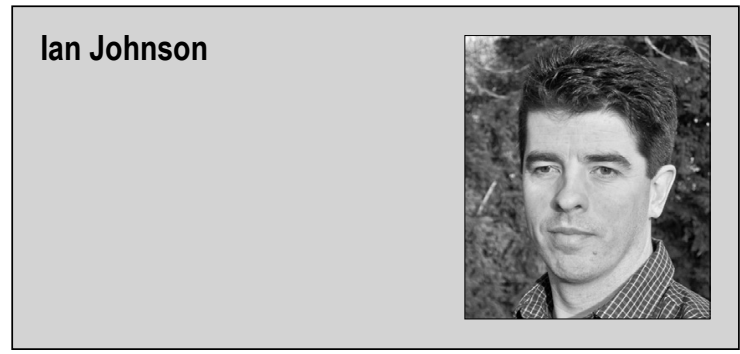

lan Johnson is an RTLB working within the Westland cluster based in Hokitika. He migrated to New Zealand seven years ago following 10 years teaching in English mainstream and special schools. Since arriving in New Zealand he worked for GSE as a Special Education Advisor with responsibility for ORRS students and Assistive Technology. He completed his Masters of Education (Victoria) following his RTLB training.

\section{Email}

rtlb_ian@hokitika.school.nz 